Article

\title{
Networking Historic Environmental Standards to Address Modern Challenges for Sustainable Conservation in HBIM
}

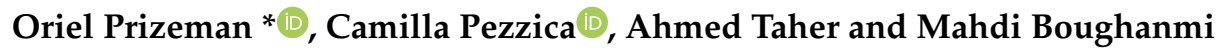 \\ Welsh School of Architecture, Cardiff University, Cardiff CF10 3NB, UK; pezzicac@cf.ac.uk (C.P.); \\ tahera@cf.ac.uk (A.T.); boughanmim@cf.ac.uk (M.B.) \\ * Correspondence: prizemano@cf.ac.uk; Tel.: +44-0-2920-875-967
}

Received: 17 January 2020; Accepted: 7 February 2020; Published: 14 February 2020

Featured Application: For optimizing the conservation planning and considerations for efficient refurbishment of early twentieth century public Buildings in the UK.

\begin{abstract}
Awareness of the logic and context of original (and subsequent) design priorities is critical to informing decisions relating to valorisation, repair, refurbishment, energy retrofit or re-use of built heritage. A key benefit of collating data through Historic Building Information Modelling (HBIM) should be to assist others facing similar challenges. Here, examples for sharing understanding of how components belong to a system are outlined in the context of a newly completed dataset of public library buildings in the UK funded by Andrew Carnegie, predominantly built between 1900 and 1914. Demands for the functionality and economy of public library buildings, coupled with the emergent standardisation of building components at the time, provide a specific condition with potential for further iteration to other buildings of the period or related typologies. The work highlights the urgency of providing cost-efficient knowledge sharing structures in an era of altered priorities with respect to energy use for modern heritage. We propose the means for mapping common features to network knowledge amongst stakeholders through relevant open source pathways. The results demonstrate that integrating geographic approaches to knowledge sharing in HBIM with environmental considerations also supports wider questions of risk management related to the stewardship of historic buildings in the context of climate change.
\end{abstract}

Keywords: networking HBIM; relational dataset; environmental paradata; design intent; Carnegie libraries; sustainable building conservation

\section{Introduction}

Ewart emphasises the extent to which the HBIM proposal in 2019 still belongs to an academic led notion [1]. Volk et al. and Lopez et al. have highlighted that the uptake of BIM of existing buildings is slow [2,3]. A respondent to the UK National Building Specification 2018 National BIM report noted: "BIM and its application to the Heritage, needs to be considered," notably the subject is not addressed 2019 [4]. This assimilation of the actual limitations of HBIM applications in practice raises a challenge to consider the potential for directly addressing the common needs of a group of disconnected and ill-resourced stakeholders. Here, we build on an extensive survey of a consistent group of buildings with the aim to enable swifter assimilation of technical knowledge. Questions regarding the appropriate Level of Detail (LoD) reflect a poor fit between academic and professional reasoning, Fai and Sydor eloquently identified the risk of overlooking the "typical" in an effort to define the "specific" with regard to HBIM [5]. 
Drawing from a recent but very different past, where building performance was highly engineered but to different targets than today, we define key parameters relevant to a substantial 'estate.' The aim is to address the means by which typical elements and their design intentions might practically be shared in HBIM, specifically with respect to energy retrofits and environmental assessments. Seeking to transcribe technical data and specification practice at scale through a new survey, we start by defining common elements whose importance is understood and whose relative incidence has been confirmed using novel machine learning techniques. These survey processes necessarily take place at a range of scales. We highlight the environmental rationale behind systems as the buildings were designed. Underlying this work is an intention to facilitate future conservation management through enhancing access to historic technical knowledge in an under-resourced context. Recognising that although priorities for environmental design have changed drastically over the last century, we aim to spotlight opportunities for a better appraisal of original design intention. Specifically, we aim to inform challenging decisions regarding critical trade-offs for proposed modifications to historic buildings justified by current responsibilities with respect to climate change.

New Historic England guidance on HBIM standards provides significant assistance in navigation between classification systems rooted in Archaeology and BIM tools largely championed by the construction industry [6]. HBIM, defined as Historic Building Information Modelling by Murphy and Heritage BIM by Yusuf et al. has expanded dramatically as a defined field of research $[7,8]$. Dore and Murphy first noted the requirement for semantic interactions between parametric HBIM objects in 2012 [9]. Much academic focus emphasises the issues of interoperability between systems as this concern was highlighted early on for BIM by Eastman [10]. Pauwels et al. applied Industry Foundation Class (IFC) templates to integrate semantics into ontological models for BIM in order to facilitate interoperability between file formats using Object Web Language [11]. Here, rather than addressing the interaction and operation of systems, we started from the observation of patterns and the potential for linking existing knowledge bases. The dataset that links them is shared in Microsoft Excel in order to prioritise accessibility and therefore potential interoperability.

In their review, Bruno et al. note that both Murphy et al. and Rodríguez-Moreno et al. advocate the development of HBIM libraries for related groups of buildings [12-14]. Emphasis is commonly placed on the lack of coherence between heritage assets and the challenges in creating sharable data when heritage assets are unique. As a consequence, current Historic England guidance on HBIM proposes the creation of individual heritage Asset Information Models [6]. The logic for this flowing from the observation above historic assets are generally one of a kind. Whilst this is true, there are still significant areas where common practices of craftsmanship, materials and building technologies can be identified. There is scope without compromising accuracy, to suggest that larger overarching data sets should be created with the aim of connecting common threads. Indeed the 1972 ICOMOS declaration relating to groups of ancient buildings is a premise later used to support the recognition of "group value" of disparate assets [15]. Indeed, the notion of group value should equally be applied to a historical technological context. Arguably, historic design aims or operational practices should be read in wider respects as a "setting" in terms of the Venice Charter [16].

Whilst Carnegie Libraries were not all designed by the same architects, their designs, in application for funding by the Scottish-American philanthropist, were reviewed in over 2811 grant bids for buildings located predominantly across Britain and America. Previous work has asserted that the subsequent building program resulted in the procurement of the largest number of buildings involving a single organisation to that date [17]. Drawings were sent across the Atlantic for approval by telegram or sea-mail and the correspondence relating to this is retained in the Carnegie Corporation archives at Columbia in New York as well as in the Carnegie UK Trust archives in the National Records of Scotland in Edinburgh.

Whereas one architect was often commissioned for a suite of Carnegie branch libraries, their similarities were not always obvious. Often, the plan would remain largely the same whilst the external appearance varied significantly such as between Manchester City Architect, Henry Price's 
designs for Didsbury (Gothic) and Chorlton (Classical) in 1915 and the more modern Withington library of 1927. In Liverpool, Thomas Shelmerdine produced Gothic, Baroque, Tudor and Arts and Crafts versions each with a very similar galleried arrangement. Features internally were often common across the nation although specified by different architects. Rooflights, for example, were typically abundant to maximise natural light from the zenith. Being single glazed, they now cause significant heat loss in winter and solar gain in summer. Coupled with varied maintenance regimes over a century, they often leak and are a common cause for buildings to be condemned. Indeed, one librarian noted that she climbed onto the library roof every year to clean the rooflights and sweep the gutters as the council would only carry out repairs to the roof, not maintenance. Nevertheless these top-lit spaces often provide delightful public environments that are very different to domestic interiors [18].

With our matched survey it is possible to recognise that Battersea Library Reference Room in London and Burnley Central library in the North of England have the same rooflight (Figure 1). Meanwhile, readers in Merthyr Tydfil in South Wales look up to the same panorama as those in Islington Central, there are visual pairs between distant interiors in Stockport and Rutherglen, Dumbarton and Teddington, Cathays and Rawtenstall. Carnegie libraries were built in places of thriving industrialisation. The degree to which environmental qualities are shared today is striking in relation to a polarising wealth and is to a great extent reflected by the nation's post-industrial decline. This socio-economic aspect adds urgency to the requirement to optimise accessible knowledge sharing tools. Diara and Rinaudo point out that the quantity of Heritage assets does not allow for unique solutions for each and make the case for a relational database [19]. To this end, the sequence of processes presented here are not necessarily all "State of the Art," the innovation lies in the assembly of an relational database which delivers a starting point for buildings whose management and care is not necessarily coordinated but whose original design intent was also highly specific and standardised. Although public building projects are taken on by larger businesses and for these, BIM is compulsory in the UK, any projects here which relate to library buildings are not procured by a single entity. For this reason, seeking to bridge a gap in knowledge by highlighting potential commonalities and thereby enabling some level of efficiency is highly desirable. To this end, the adaption of HBIM parameters to acknowledge and inform decision making today by tying them more closely to the ambitions and specification of the past has been a key goal of the Shelf-Life Project, which addresses the future of the 224 remaining open Carnegie Library buildings in Great Britain and Northern Ireland. By collating data which can subsequently be connected to other buildings of the time through their architects, architectural features or specifications that have been identified, it aims to provide a robust starting point for networking the construction knowledge of a very prolific era of building in the UK. 


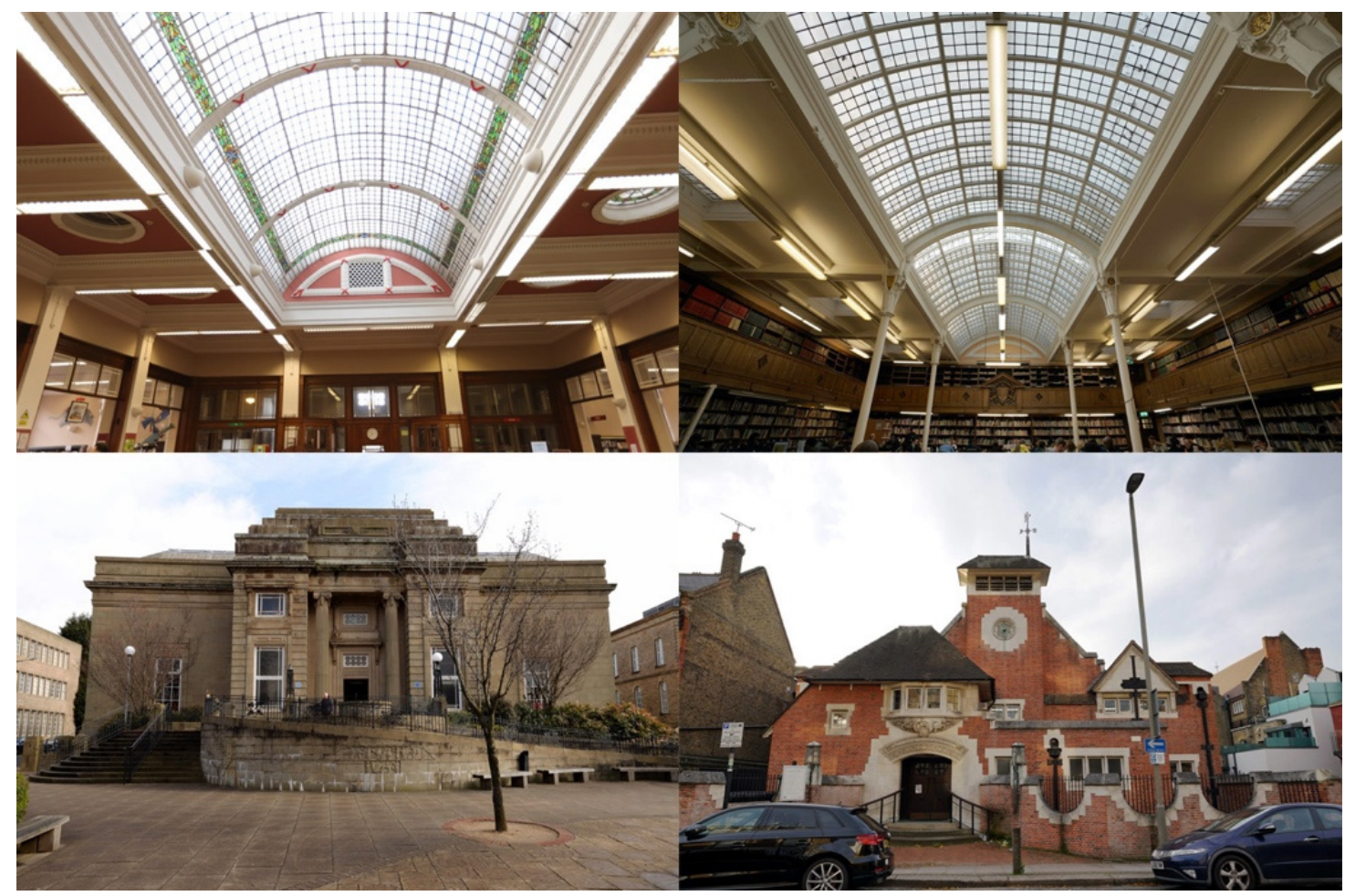

Figure 1. Left: Burnley Library Facade and Interior, A Race, 1930 Right: Battersea Reference Library Façade and interior, H. Hyams, 1924.

\subsection{Ambitions and Realities for BIM and HBIM-An Update}

The envisaged 'potential' of BIM has had a long incubation with respect to existing buildings. For the first time, a new International standard for BIM, ISO19650-2 BSI [20], establishes the existence of pre-project asset information and project legacy information. Howell argues that "An enhanced BIM specification has the potential to introduce a paradigm shift, promoting a new performance-based approach where intangibles such as intellectual capital, customer and societal values transcend the traditional practices that lead to the delivery of the building product" [21].

\subsubsection{Sustainability}

The US National Building Information System (NBIS) announced in 1992 that the intention of BIM was to mitigate the environmental impact of buildings through materials, energy use and waste [22]. Later this was underpinned by a statement by the US department of the Interior: "We must make the rescue of the environment the central organising principle for civilization" [23]. In 2015 the UK Government required all public building projects to use BIM and implied an emphasis on existing assets "this means using modern technologies to get more capacity out of our existing infrastructure" [24]. It might be assumed that this intention would sit well with that of sustainable building conservation management and practice. However, research has shown that the significant majority of BIM activity in the UK happens in the design phase or preconstruction phases of new projects [25].

\subsubsection{Accessibility and Interoperability}

Issues of interoperability between systems have predominated. Two European H2020 projects, INCEPTION and DURAAK, set out to deliver semantic tools to contribute to the application of historic knowledge with BIM models [26-28]. Closely related and very relevant to the context in question, is that of cost. Murphy et al. highlighted the economic challenges of HBIM which is reliant on high cost hardware, software and expertise [29]. In line with Quattrini et al. they advocate the potential of web-based game engines to accelerate the availability of more affordable and accessible tools [30]. 
Logothetis et al. promote the deployment of Free Open Source Software FOSS [31]. To this end, it is clear that survey data as well as the means to deliver it must be made readily available notwithstanding professional concerns of liability that have traditionally resulted in standard statements on architects' drawings such as "all dimensions to be checked on site".

\subsubsection{Level of Detail}

Traditional methods of 2D documentation and design drawings at a range of scales benefitted from a refined logic of diagrams that could enable a translation between the "typical" and the "specific" in terms of Fai and Sydor [5]. With the capacity to acquire data being so advanced by digital tools, many wrestle with the means to proceed pragmatically. A laser scan may show surface detail but it does not reveal construction build up in the way that a sketched detail section could. The translation from scan-to-BIM retraces the steps of a site survey without leaving the computer. As noted by Nieto-Julián et al. there are significant potential discrepancies between the parametric or idealised BIM model and the deformations evident in measured survey, these are of course particularly critical with respect to structural modelling [32].

There are other purposes however, for which such accuracy is not so critical. Carnevali considered the process of deriving BIM models for two existing railway stations, highlighting the pragmatic challenges of deciding on an appropriate level of detail-and also setting out comparative LOD standards for USA, Italy and UK [33]. Fassi and Parri developed a 3D WEB BIM for the recording the complexities of Milan Cathedral at varying levels of detail [34]. The interface has been re-used and in particular enables multiple actors to contribute to and benefit from the web browser interface-see Tommasi et al. [35]. This feedback from practice as an acknowledgement of the different needs of various stakeholders is important.

Indeed, by contrast, traditional methods of orthogonal drawings, cross-referenced between details and schematics at a range of scales serve a critical purpose in enabling the unambiguous and efficient transmission of relevant information between agents. To some extent, the ambitions of politicians driving the uptake of BIM for all public projects in the UK from 2016, the US National Building Information Model Standard, the work of Barazzetti et al. on the Collemaggio in L'Aquila and Fai et al. in Ottawa, are examples of a top-down incentive driven by a desire to appear to be state-of-the-art $[23,36,37]$. It is beholden also to reason from the bottom-up if the scope of this mission is to be crafted to good use. With respect to the latest Italian BIM standard: UNI 11337: 2017 for BIM, Maiezza has proposed a new standard to allow the documentation of various degrees of certainty or completion for HBIM objects which could be useful for the co-operative expansion of such paradata [38].

\subsubsection{Classification}

Whilst BIM is developed in the construction industry with classification systems that have developed from a system of specification based on trades [39], archaeologically based classification systems do not readily relate to that logic and as a result, the lists become longer and longer. In archaeological and museum contexts, the use of semantic data tied to knowledge ontologies to inform layered knowledge acquisition is well developed. The Getty Linked Open Data (LOD) program and CIDOC (International Council for Documentation under the International Council for Museums) Conceptual Reference Model (CRM) provide standards for integrated cultural heritage data [40,41]. In theory, tested models of Parisi et al. are available for adding to emerging BIM ontologies for Heritage (HBIM) [42]. Whilst one might anticipate a truly significant reliance on standardised BIM objects in the UK since the government's mandate for BIM on public projects came into force in 2015, the NBS 2019 survey reveals that $62 \%$ of architectural practices in the UK still create their own BIM objects in house for new buildings, indicating that adoption of BIM is something of a cottage industry even for new-build projects [43] p. 33. 


\subsubsection{Semantic Enrichment: Showing Design Intent}

Recognition of components is useful, however reading their part within systems is also necessary. Indeed the 2019 NBS survey of BIM usage in the UK notes an increase in the use of non-proprietary Construction Operations Building information exchange (COBie) files, which allow the sharing of non-geometric information about a building [43] p. 31. With respect to BIM, Sacks et al. determined that improving semantic enrichment was critical to enabling Life Cycle Analysis (LCA), for developing BIM for existing buildings and for Scan-to-BIM endeavours [44]. Relevant to this research, a recent paper by Morganti et al. seeking to address HBIM protocols for early twentieth and late nineteenth century steel structures in Italy, suggests an intermediary stage in the knowledge gathering process of a "Building Components Census" this allows discrimination between standardised elements that are still made, that are not still made that were bespoke [45]. This step enables families of components to be pre-defined before modelling.

That heterogeneous construction build ups are not necessarily currently supported by the Uniclass system in the UK as has been highlighted [46]. However, systems of interrelated elements may also operate at a wider level, for example as part of a standardised a ventilation system or a system of storage in a library. In turn they may belong to a family that is a characteristic attribute of a particular building typology, era or region. In current BIM guidance, the potential for design intent to be recorded is set out using the example of a finishes schedule in a clinic [47]. It should therefore be possible to augment such data in order to record historic design intent, this might relate to a number of alterations over time but in sum it would contribute to the understanding of the building morphology and so inform its conservation.

\subsection{Principal Conclusions}

We have determined that rather than the 660 previously claimed [48], a total of 469 library buildings were built using Carnegie funds in the UK. Of these, 424 buildings survive. Although a large proportion were more modest Village Halls with Reading Rooms, the majority were library buildings of which 224 are still in use as libraries. Today, with funding challenges for public services, many are at risk of closure and others struggle to keep maintenance demands at bay. Our research determines that although 121 have been re-purposed, 28 buildings are currently closed, empty and at risk. In parallel, governmental demands for all public buildings to have BIM models appears to demand a bank of common knowledge. The means to develop and share the parametric attributes of typical features of such buildings coherently have been determined in terms of their capacity to offer broad pathways towards intelligent maintenance and efficient refurbishment or potential future re-use.

\section{Materials and Methods}

In this research we have sought to engage with historic standards in order to develop a new methodological approach with the advantage of building on a specific technical knowledge base but that also makes use of accessible platforms for dissemination. Quattrini et al. detailed a case study demonstrating how a range of data are applied semantically using a Resource Data Framework (RDF) and an Ontology Web Language (OWL) [48]. Acierno et al. developed an ontological structure for conservation planning in consultation with conservation professionals, in focusing on data relating to conservation activity as opposed to facilities management or physical description alone, it is unusual. The project defines four knowledge domains; "artefact, lifecycle, heritage investigation process and actors." However, the work largely deploys classes established by the CIDOC Conceptual Reference Model as opposed to the more relevant architectural classification system of architectural specification suggested in respect to this research [49]. Xiucheng et al. have sought to combine HBIM

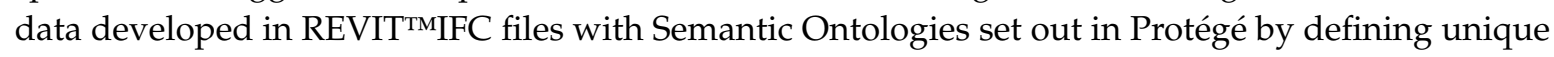
identifiers to link them [50]. Using CIDOC CRM identifiers to build ontologies on a standardised platform, they finally propose the extension of REVIT ${ }^{\mathrm{TM}}$ using Dynamo to augment segmented models 
with ontological data which is visible at the same time. What is useful is the promised potential to move beyond classification and documentation of the heritage asset to also associate with previous decisions, moments of transformation such as previous repairs or condition monitoring. The linkages between data properties or object properties in OWL are given values modelled in relation to the conceptual domains to which they may connect. Critically, the ontology allows for elements to be identified as part of an assembly or system.

Although funding the collation and application of sufficient data would appear daunting for many buildings and sites, in principle such a resource potentially provides a three dimensional conservation management plan as proposed by Kerr and advocated by ICOMOS [51]. However, the means to deliver or define the limits of such data to collate for buildings with marginalised means are a critical concern. Therefore, here the creation of a network based on a typology in a restricted era which can deliver adaptable HBIM libraries through the geographical identification of standardised components, assemblies and systems relating to existing classification indices, is a valuable step forward. Previous work had noted the potential to link HBIM models to historic specification clauses offering further potential to expand the relevance of the data [52]. The ability to infer historic design intent will become greater as the quantities of elements recorded increases.

Here, taking elements understood to be typical of a system, we have sought pathways to augment the data relevant to them in a means that should be accessible to the stakeholders likely to work on them. The additional data is intended to inform both their valorisation and conservation treatment. The steps to anticipate, survey, adjust, interpret, confirm and finally re-map these findings are not necessarily sequential, rather the process has been iterative with one process at one scale correcting or informing another. The methods are necessarily interdisciplinary, requiring archival research, GIS mapping, photogrammetric and laser-based digitising, CAD modelling and interaction with practitioners and stakeholders. A Computational Fluid Dynamics (CFD) analysis of a typical ventilation system is illustrated to demonstrate an environmental system of ventilation in principle. A photographic survey of all 424 the Carnegie library buildings externally and 224 open libraries internally was used in a classification exercise using deep learning techniques to test the notion of automated object recognition at scale.

López et al. highlight the need for a free access HBIM library with shape recognition algorithms [3]. Chen et al. present an image-based recognition system "fuzzy-MAUT" - using a relatively modern building, they successfully automate the development of IFC BIM elements [53]. Oreni focused on the creation of a library of vaults and proposed the semantic relationship between similar historic objects [54]. By comparison, here, in order to scale-up the image matching process and cope with larger datasets, an advanced classification model was devised which could automatically recognise characteristic building components relevant to HBIM such as, skylights, barrel vaults, glazed domes, wooden panelling, internal glazed partitions, ceramic tiles, ventilation turrets and grilles.

Subsequently detailed surveys of 22 buildings were made with a FARO x130 3D laser scanner enabling parametric models to be made of some typical elements. The intention is to contribute components to the NBS National BIM library to serve future practitioners addressing the repair, rehabilitation or restoration of these common elements but also to inform those engaged in listing and designation tasks. To this end the common features that have been identified are located and mapped in GIS enabling a relational network to be established between disconnected stakeholders with potentially similar conservation and maintenance issues. All these aspects are logged in a spreadsheet which enables a significant potential for correlational observations but most importantly, for sharing and therefore not always repeating conservation related research in isolation. Ultimately this will all be available on a website, here, the dataset is provided as supplementary material [55]. The sequence of methods used are illustrated in Table 1: 
Table 1. Sequence of methods.

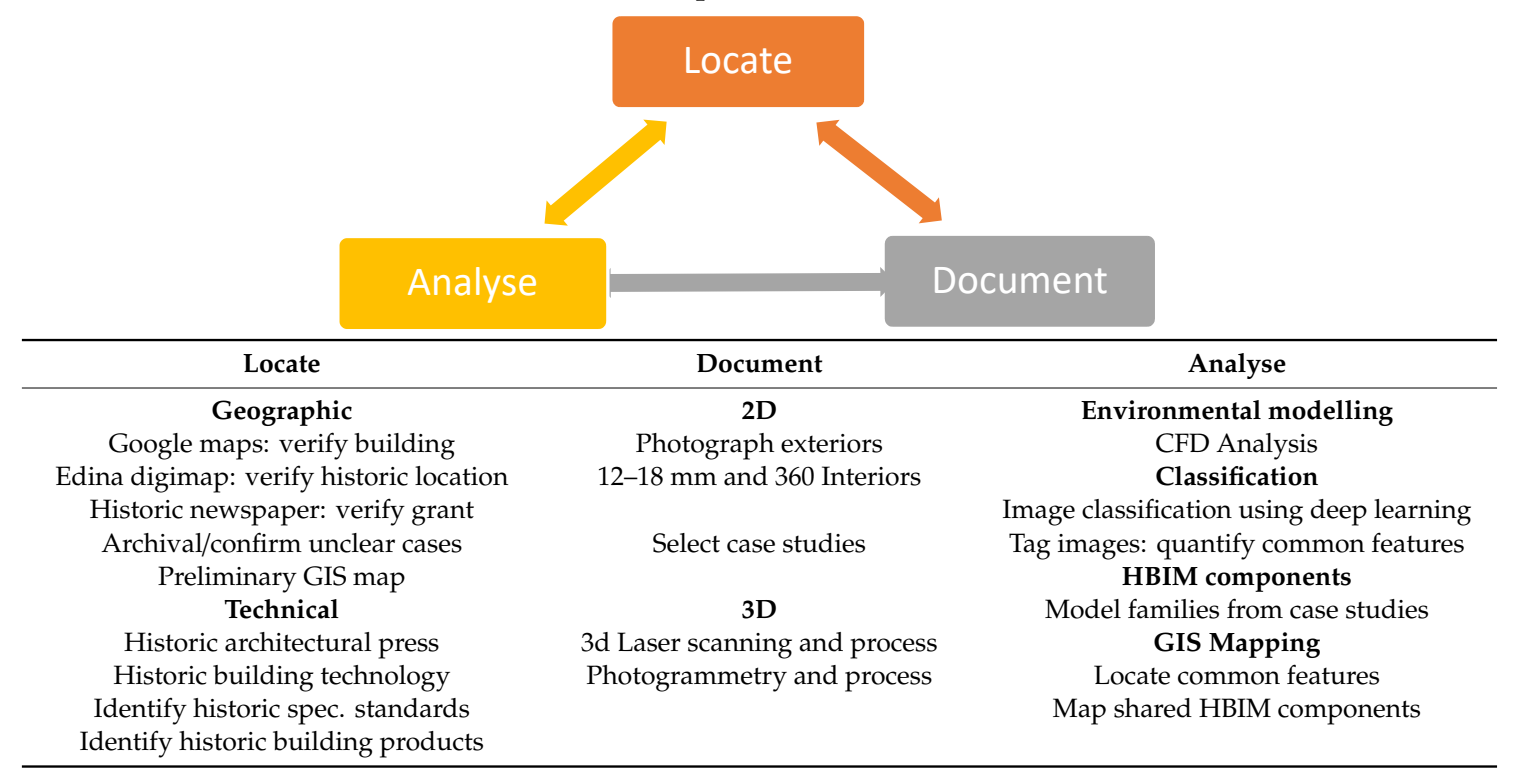

\section{Results}

\subsection{Survey}

Our recent 4 year comprehensive survey firstly cross-referenced between the various published lists of the Carnegie Corporation, a gazetteer of UK public libraries [56], the various statutory lists of buildings in England, Wales, Scotland and Northern Ireland and preliminary verification of buildings on Google Earth ${ }^{\mathrm{TM}}$. This was followed up with searches to determine the location using historic Ordnance Survey maps through Edina Digimap ${ }^{\circledR}$, to verify the grant application and acceptance in council minutes reported in historic local newspapers using British Newspapers Online and the correspondence in the archives of the Carnegie UK Trust, together with collation of all existing references and illustrations in the contemporary architectural and construction press form the Royal Institute of British Architects (RIBA) and Cambridge University Libraries. Finally, on site recording for the first time to photograph the exterior of all buildings and interiors of those still in operation as libraries. A central spreadsheet containing all the relevant data and source material was used to update the process together with a preliminary GIS map to facilitate the planning of site visits. Each photographic record of the building, record or map was subsequently tagged with keywords enabling swift sorting of commonalities between the spreadsheet and the buildings.

\subsection{Recognising Historic Design Priorities:}

In following guidance on library design, priorities changed radically over the course of the twentieth century. Whereas in leading guidance in 1897 "Natural and Artificial Lighting-Heating and Ventilation" was the title of Chapter 2 of "Library Construction; Architecture and fittings" [57]. By 1973, in "Planning and design of Library Buildings," the author postponed "Lighting" and "Physical conditions-Heating and cooling - humidity-noise" to the 15th and 17th chapters respectively [58]. This reflects a reversal of priorities in the briefing and execution of library design and all other building design aided by the technological evolution of the twentieth century.

In line with their counterparts in the US, the majority of the Carnegie Libraries in Britain, built up to the start of WW1 were constructed at a time of plentiful and skilled labour using high quality materials. Although ostensibly traditional, as with many other buildings of the period, they were leanly engineered in terms of their environmental performance as emphasised in earlier work [48,59]. It is a transition which is far less apparent than the visual transformation of architectural styles over the 
period. However, poor thermal performance is a critical cause of building failure and abandonment. Indeed, a recent book includes a review of refurbishing a listed library building in Staffordshire which notes: "The need for a bright, modern and attractive environment does not sit easily with Victorian grandeur and austerity" [60].

The fact that a vast proportion of public libraries (and public buildings) in the UK were built at a time when artificial (electric) light was extremely expensive and heat was cheap, the opposite of our current situation, has caused significant challenges for their subsequent maintenance and upkeep. Buildings that were engineered specifically to provide expansive areas of top lit "sky view" with vigorous ventilation systems supporting the intake and extraction of heated air have become leaky, draughty and expensive to heat. In effect, with the possible exception of daylight provision, the performance specification of these buildings has reversed. Nevertheless historic insights into adaptive economies with respect to the use of artificial light might lend insights to our current priorities: For example, Breisch noted that cast-glass floors were first developed for library buildings in order to share what little of it there was between levels [61]. Papworth recorded in 1853 that the British Library would open and close at times determined by hours of daylight [62].

Meanwhile, however, although despised for their pompous traditional appearance in the 1970's, today they are increasingly recognised as buildings of special architectural interest, we have determined that 225 of these buildings are now designated for statutory protection. The requirement to conserve them well requires the adoption of an informed and careful approach with respect to their intended performance as designed and the challenges of justifying or modifying these features in terms of energy usage in the context of an awareness and determination to mitigate against the impacts of climate change. The period of construction under review was one that benefitted from significant advances in material production and the start of standardisation of building components.

\section{Vaulted Ventilating Ceilings in Principle}

A common feature of these (and many other public buildings of the time) was the use of the curved ceiling and associated ventilating turret. As previously outlined, these ceilings were used to encourage the adequate ventilation of buildings where anxiety over the exchange of disease in public spaces was deemed a key risk [17]. In 1907, Champneys' contemporary architectural design advice firmly advocated the need to allow for adequate airflow [63]. In 1824, Tredgold had advocated the design of a vaulted ceiling with a ventilating grille at the top [64]. By the end of the nineteenth century, numerous patent turret ventilators were available for specification from increasingly indexed compendiums and emergent specification handbooks such as Rogers [65]. Methods of tracking building products are better developed in North America where the Association for Preservation Technology International have been building an online digital library of technical and product literature- this is not, however, so readily available in the UK-in fact in many cases, academic libraries would tear out the advertisements at the front and rear of journals before binding them, thereby losing much of this rich data.

Here we have undertaken a CFD analysis of a typical building to underline the performance to a vaulted ceiling ventilation system. Advances in environmental modelling in HBIM are based on monitored data or the assimilation of visual condition mapping of individual historic assets [12]. However, modelling is an expensive endeavour and therefore understanding a system in principle is also a valuable objective if its findings can reasonably be applied in principle to providing a better understanding for a group. Here, we propose a single ventilation reference model for the typology at the time and use results derived from matching techniques to extrapolate potential reiterations through the identification of common features associated with this system see Table 2. 
Table 2. Incidences of Internal Features across all open UK Carnegie Library buildings. Source: Authors.

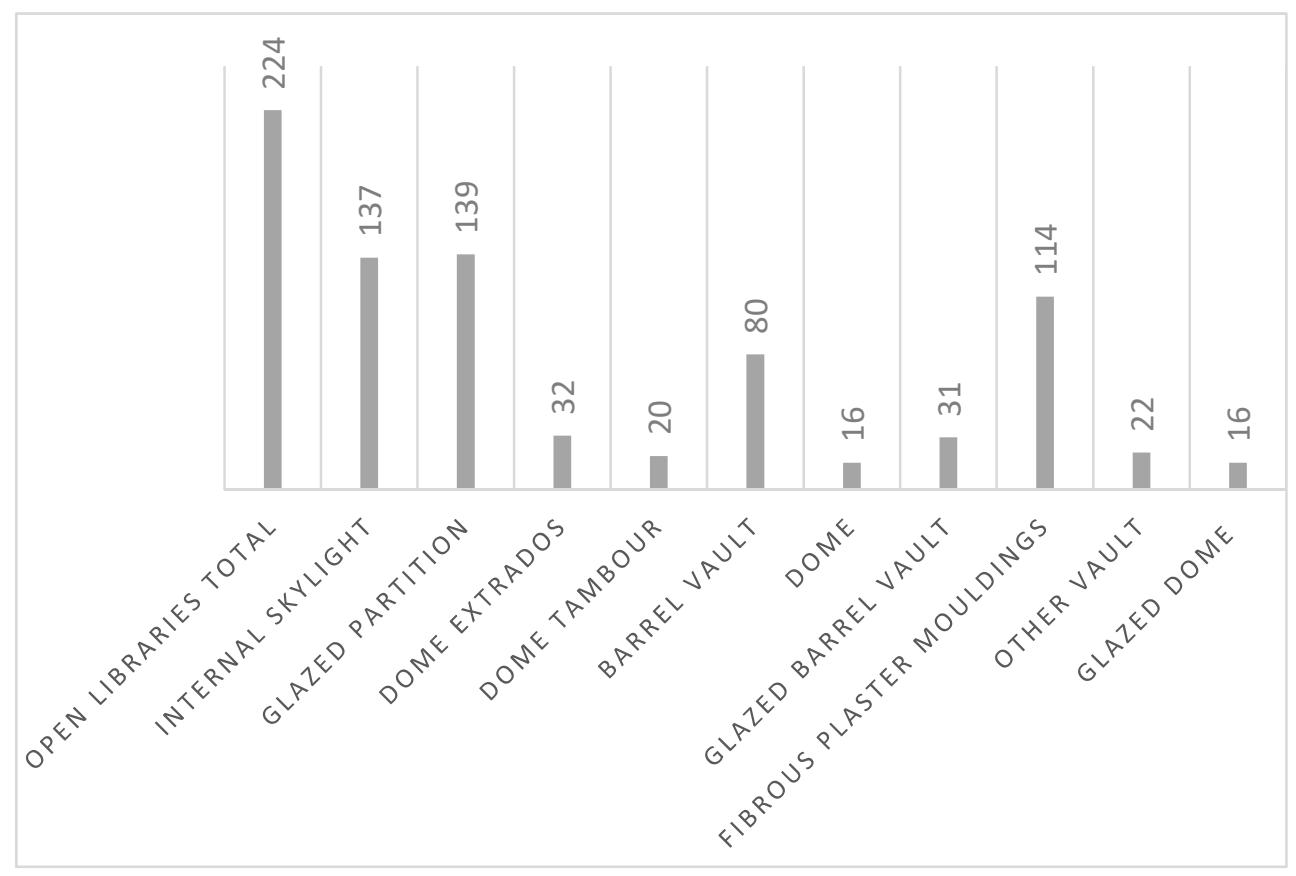

\subsection{A CFD Ventilation Reference Model}

Library buildings have a long legacy of using curved ceilings, relating as domes traditionally have done to a celestial order. The pantheon was initially recreated as an extruded vault and idealised in Boullée's design for the Bibliothèque Nationale, later adopted in Labrouste's Bibliothèque de Sante Géneviève and McKim Meade and White's Boston Public Library. Meanwhile the panoptical plan and pantheon section of the British library and of Jefferson's proposed library for the University of Virginia exemplified the expectation of an arrangement of physical access to knowledge whose ceiling was representative of celestial horizons. By the mid nineteenth century, further pragmatic aspects were added to this context as ventilation became a priority. In addition, the manufacture of curved ceilings was made significantly simpler by the advent of fibrous plaster panels, with cast decorative details prefabricated to bespoke dimensions from catalogues. Our research shows that such ceilings are evident in 80 of the 224 open Carnegie Library Buildings in the UK. They also appear in many other public buildings of the era. The quantity of these elements demonstrated by our research justifies the investment of time in creating informed parametric models and related data to share with relevant stakeholders.

A CFD model was made of a relatively un-altered branch library, Cradley Heath Library (Arch. Crouch Butler and Savage, 1908) (Figure 2). The analysis demonstrates the principle of a heating and ventilation system which relied on the incorporation of a barrel-vaulted ceiling. It illustrates how fresh air was drawn through cast terracotta grilles at low level in external walls behind the radiators and the warmed air was then drawn by the propeller within the turret at the top of the ceiling in order to accelerate the continuous process of warming and ventilation.

The commercial numerical simulation code Fluent 18.1 was used to perform the computations for the assessment and evaluation of air movement patterns for the simulation Figure 2. Although it is recognised that CFD results are subject to uncertainties and approximations, the achievement of consistency is related to the control of a number of input parameters. 


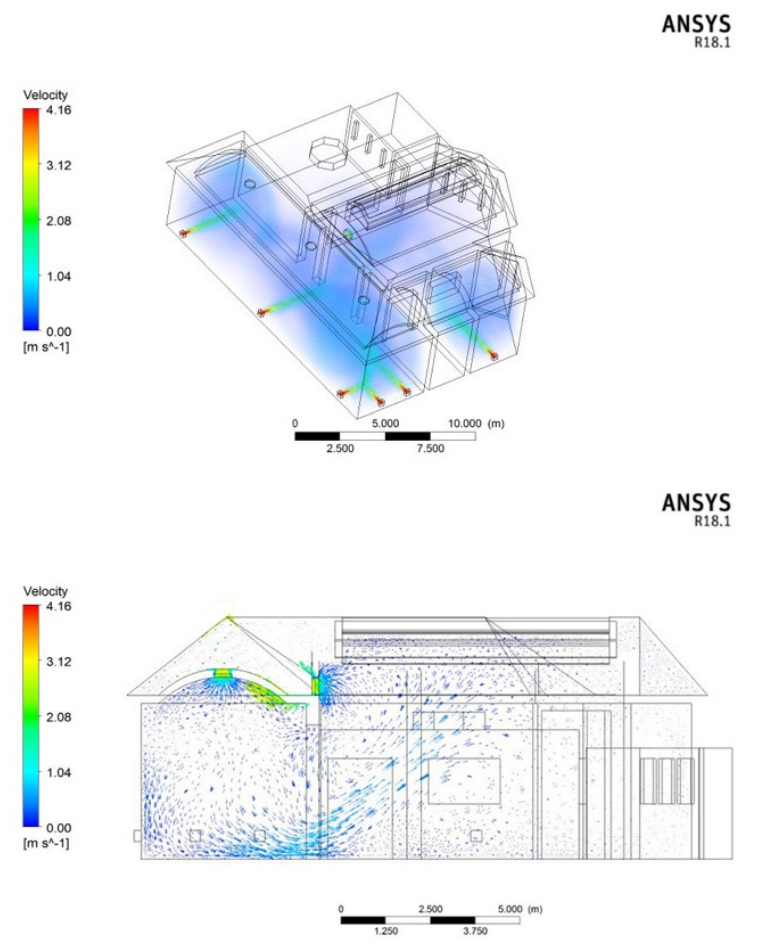

Figure 2. Computational Fluid Dynamics (CFD) simulation model Cradley Heath Library.

\subsubsection{Model, Domain and Boundary Conditions}

A model for the library building was constructed with its complete internal spatial configuration including all openings, interior partitions and doors. The boundary types used were velocity inlet, interface, non-slip walls and outflows according to the principles established by Franke et al. [66]. No penetration and non-slip conditions were imposed at all solid wall boundaries. The supply air vents visible in external terracotta grilles were defined as the velocity flow inlets. The pressure outlet boundary was imposed at the exhaust outlet system embedded in the ceiling and connected to the external turret. The supply air is assumed to be sent into the room with a constant flow of $0.8 \mathrm{~m} / \mathrm{s}$. The fluid was set for air at constant density $\left(1.19 \mathrm{~kg} / \mathrm{m}^{3}\right)$ and viscosity $\left(1.79 \times 10^{-5} \mathrm{~kg} / \mathrm{m}-\mathrm{s}\right)$. The operating pressure conditions of the domain were kept at 101,325 Pa, the gravitational acceleration at $-9.81 \mathrm{~m} / \mathrm{s}^{2}$.

\subsubsection{Mesh Structure and Solving Parameters}

For grid generation, the main consideration is the accuracy of a numerical "solver" in modelling the airflow profile. In this study the grid had 1,454,295 tetrahedral cells used for the CFD numerical computation by compromising the accuracy and computational resources. The CFD domains were designed for minimum blockage, with an average value of 3.2\%. The "solution solver" was set as pressure-based and in implicit mode for steady-time problems. The turbulent viscosity model adopted

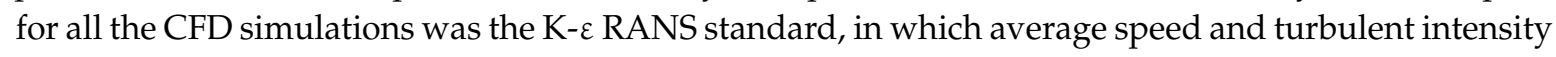
profiles were used.

\subsubsection{CFD Simulation Results}

The airflow inside the library throughout the simulation air speed was moderate demonstrating that airflow would not be not felt in most regions. The airflow supply through the inlet vents were located in the publicly accessible areas of the building. Internal windows helped to induce airflow to the central hall zone within the building and some of the other spaces with an uneven airflow distribution. The exhaust outlet position in the ceiling combined with the vaulted shape is seen to enhance the airflow magnitude and circulation within main reading area and the central hall. Simulation results 
confirm that the natural ventilation system would have guaranteed an adequate internal air movement within the main reading area while other, less populated, spaces would not perform as well. The stack effect ensures continuous air exchange and better indoor air quality within the reading area with what would be stable and comfortable internal microclimatic conditions.

While the mechanical elements of this ventilation system no longer function in any library that we have seen, its components are evident in a significant number of buildings. It would not be obvious that the purpose of the vaulted ceiling was originally related to the function of ventilation as opposed to decoration. Therefore, making this principle apparent is a vital driver for intelligent heritage refurbishment and conservation with respect to energy use in the future of these and many other buildings of the era.

\subsection{Identifying Patterns: Matching and Recognition}

Given the unique formal characters and visual complexity of many of these elements, the Photos-to-Specifications-to-BIM workflow proposed in this project was best supported by using a customised deep learning classification model. With characteristic end-to-end architecture, which trains simultaneously representation learning and classification, the model allows the tailoring of feature learning to the needs of the classification task at hand. This approach overcomes the need of having input features generated independently of the training process, which is typical of traditional machine learning methods such as kNN, Support Vector Machines and classic Classification Trees [67-69]. Furthermore, a sensible sizing and training of the model and the very existence of a critical mass of well documented examples of historic buildings designed using standard architectural components, allowed the exploitation of deep learning effectively and overcame the risks of poor performance connected to overfitting of images.

Previous work has confirmed this hypothesis through a comparative test of the performance (measured class-by-class using the relative F1-scores) of 3 different machine learning architectures in the classification of different ventilation building components [70]. The results indicated that a Feature Pyramid Network classification model (FPN, Figure 3) outperforms a high-end Traditional Machine Learning model (TML) composed of SIFT, K-means clustering and standard RF, by an average $26 \%$ on all the 4 examined classes of objects. To identify the regions of the images that are most relevant for the deep learning algorithm to classify an object correctly, the study exploited a state-of-the-art interpretability tool, Grad-CAM [71], which highlighted these in a coarse localisation map (see Figure 4). This approach generalizes a technique known as Class Activation Mapping (CAM) by extending its application capabilities to a broad range of $\mathrm{CNN}$ model families.

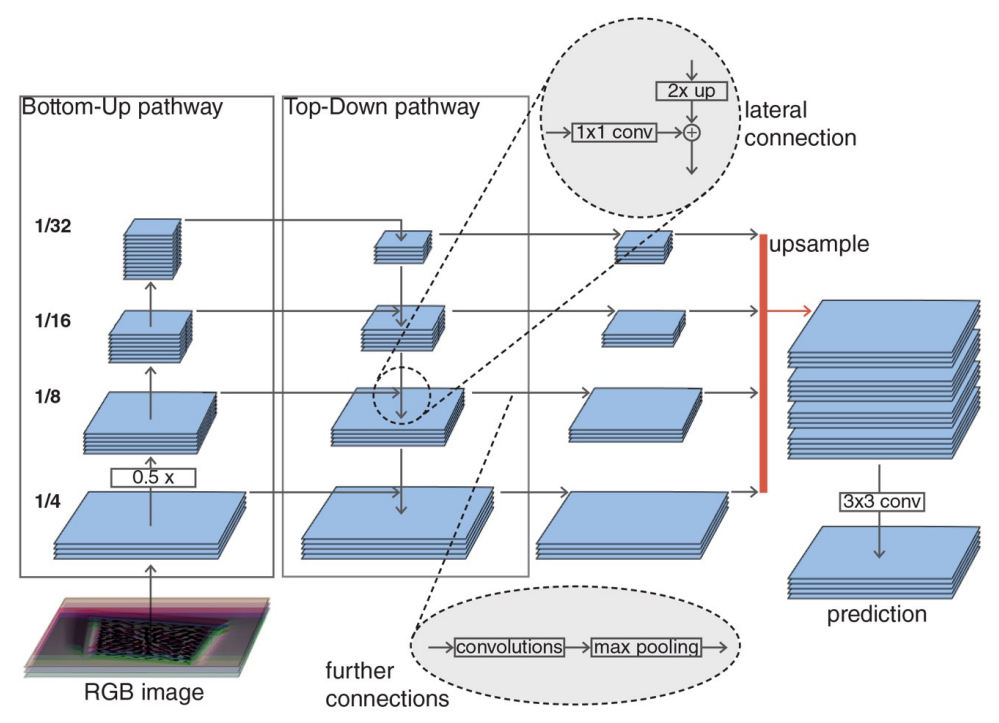

Figure 3. Feature Pyramid Network (FPN) model. 

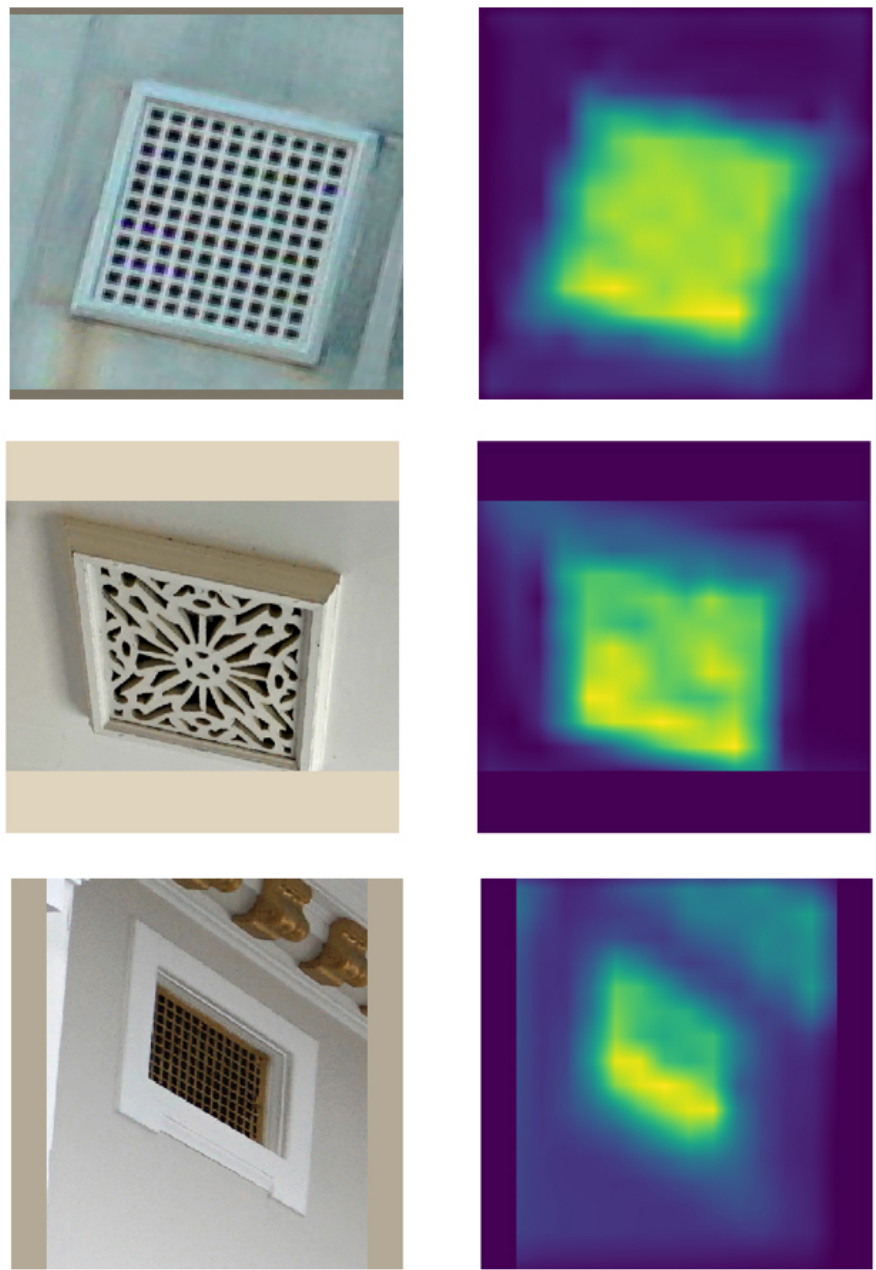
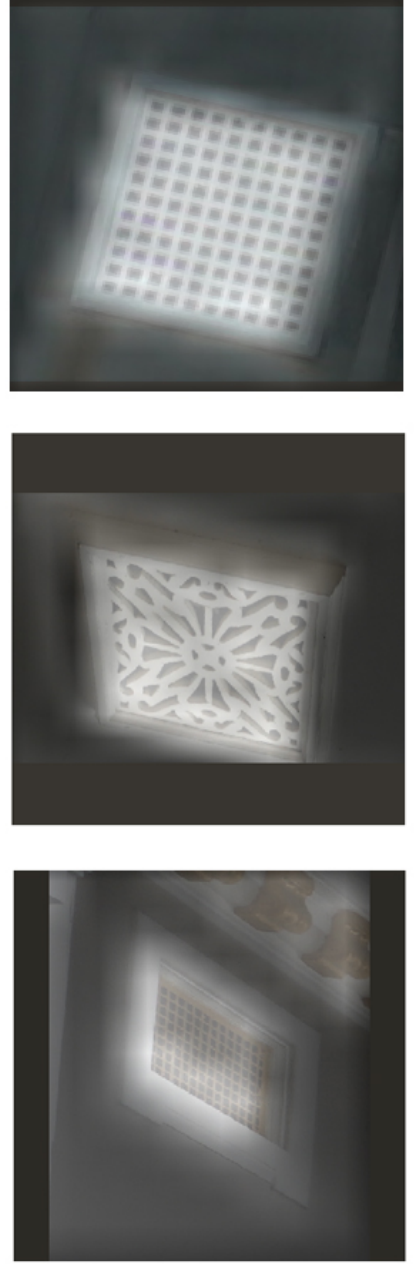

Figure 4. Gradient-weighted Class Activation Maps (Grad-CAM) of ventilation grilles.

Prior to the classification process, all images were tagged using a pre-defined set of keywords, enabling the location and quantity of identified objects to be ascertained and summarised. This provided a valuable pathway for the targeted dissemination of informed HBIM data and relevant guidelines in a resilient manner. From this, it is possible to correlate data for the entire "estate" including original build date, architect, plan-form, listing (designation) status, notes on condition, location and management organisation (local authority, contractor or community group). In collating a database, we have been able to state the instances of identified elements. Using this as a basis it is then possible to relate relevant technical literature, environmental models in principle and HBIM components at scale. Through that we are in turn able to determine all buildings with the same potential conservation issues and to proffer potential information exchange between them on best practice.

\subsection{Parametric Models of Typical Systems and Their Components}

From the photographic survey, twenty-two buildings were selected for detailed interior and exterior surveys using a Faro Focus x130 3D Laser scanner (Figure 5). The buildings were selected using a number of criteria to reflect representatively geographic location, scale, material, level of conservation and design paradigms as far as was practicable. 


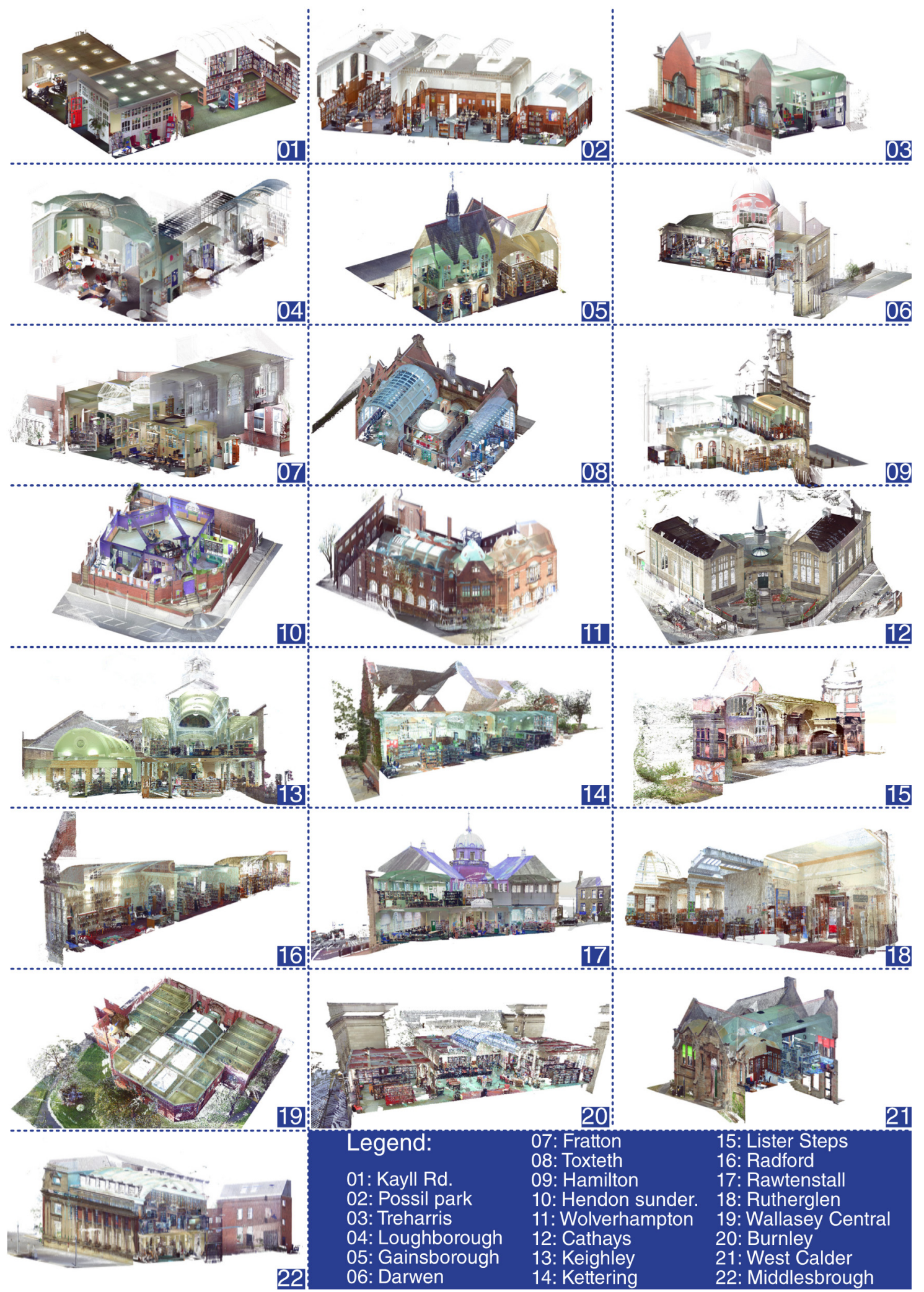

Figure 5. Laser scanned libraries.

Using the point cloud and pictures, 3D parametric models were constructed manually in REVIT ${ }^{\mathrm{TM}}$ accurate enough for an as-built verification and comparative analysis of three libraries. Models of vaulted ceilings at Possil Park in Glasgow, Loughborough and Middlesbrough libraries were made 
as exemplars at different scales. Middlesbrough Library is the largest Carnegie Library in the UK after Edinburgh Central Library. Its first-floor reading room measures $253.38 \mathrm{sqm}$ and has an apex ceiling height of $8.73 \mathrm{~m}$. It is possible to identify the ribs of the vaulted ceiling structure, the dormer windows between them together with the central ventilating grilles and recognise a prime example of standardised design with respect to ventilation. In Possil Park Library there are two reading rooms with vaulted ceilings of different sizes. The main reading room area is $142.38 \mathrm{sqm}$ and curved ceiling height of $6.44 \mathrm{~m}$. The second room is smaller in size which area measures $62.81 \mathrm{sqm}$ and curved ceiling height of $4.06 \mathrm{~m}$. The functional role of most cast plaster barrel vaults in these case studies is concealed by their decoration. Their ornate plaster mouldings and panels are also used to frame mechanical components such as skylights and ventilators. The task of identification in the variety of these decorative profiles is best directed straight back to the manufacturers' catalogues. Yet this is much easier than seeking to identify a bespoke profile as the number of manufacturers of cast plaster elements was relatively limited. It was the span and overall arrangement of the vault that might alter from building to building and so is the key parametric object.

To date, REVIT ${ }^{\mathrm{TM}}$ family editor does not allow the direct importation of a point cloud. Two options for importing data were used. Firstly, using 'in-place' family mode, building the geometry relative to the point cloud with reference planes and parameters, then pasting geometry out to a true family before completion. Secondly, creating views or sections with dimensions exported as images. Images in family editor are then the basis to build the geometry which needs a scale added. Since REVIT ${ }^{\text {TM }}$ does not allow the creation of custom shapes with the Ceiling tool, one option is to use a simple extruded "Roof" command, placing a component using the barrel vault as a host with "families" category "roof" selected. The other option is to create an in-place family. Using this technique, a ceiling family object created will now be read by REVIT TM as a ceiling, making it possible to associate ceiling-based components with it. For simplification and consistency in the creation of such families, these decorations are therefore better modelled in the same family so that they move with the host elements and can also be tweaked directly within the family parameters.

Although without the external data the modelling is limited to the internal aspect of the components, it is not possible to get accurate information related to the components such as thickness of roof construction, skylight frames and so forth, it is possible with the benefit of archival research into building products and practices of the time to provide access to a more limited range of probable arrangements of the superstructure (Figure 6). Whereas a traditional process would have involved drawing a detail section at 1:1 or 1:5 or even simply noting a catalogue reference for a profile and then a 1:20 drawing would have set out such items as desired, an HBIM model demands too much detail and is relatively inflexible. Simple assumptions that would be covered by trade knowledge such as the appropriate make-up of mitred junctions between joinery profiles are not easily created in parametric models made in REVIT ${ }^{\mathrm{TM}}$ which remains a clumsy tool in this respect (Figure 7). 

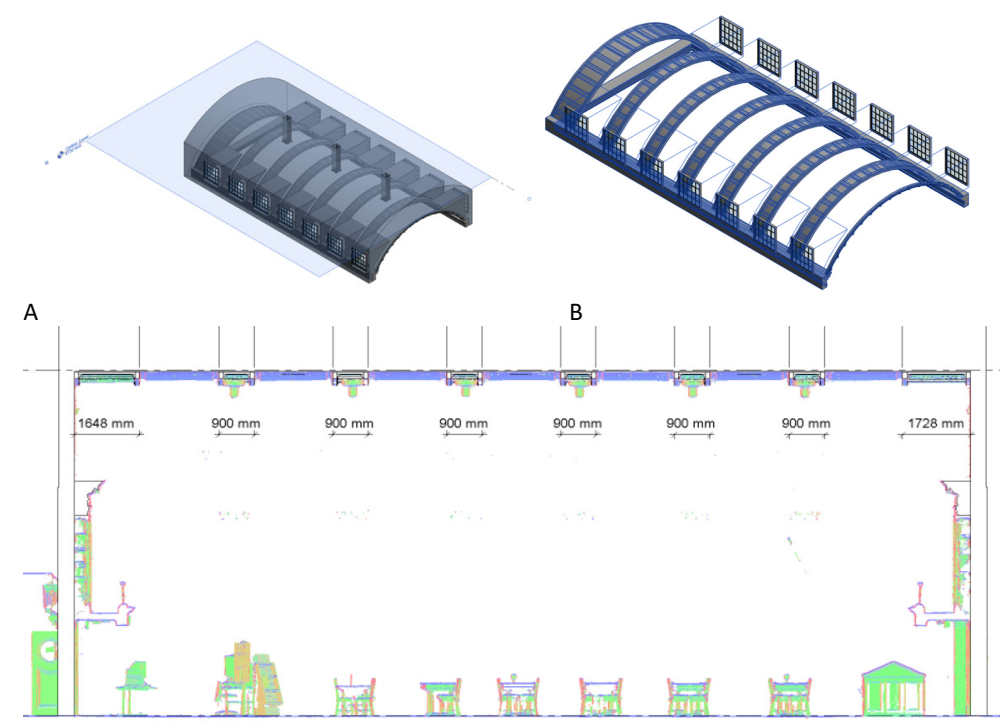

C
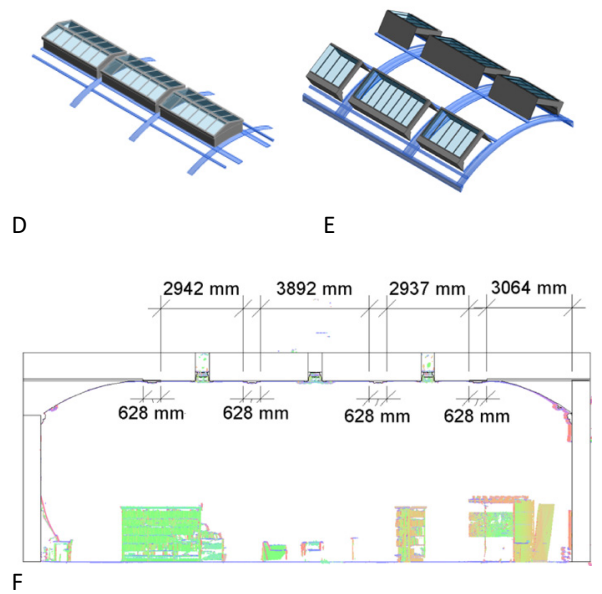
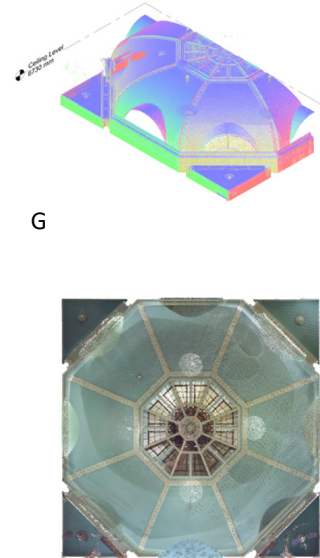

Figure 6. (A-C) Middlesbrough Library vaulted ceiling structure models and section (D-F) Possil Park Library rooflights and section (main reading room), $(\mathbf{G}, \mathbf{H})$ Loughborough Library ceiling orthophoto and model (main reading room). 

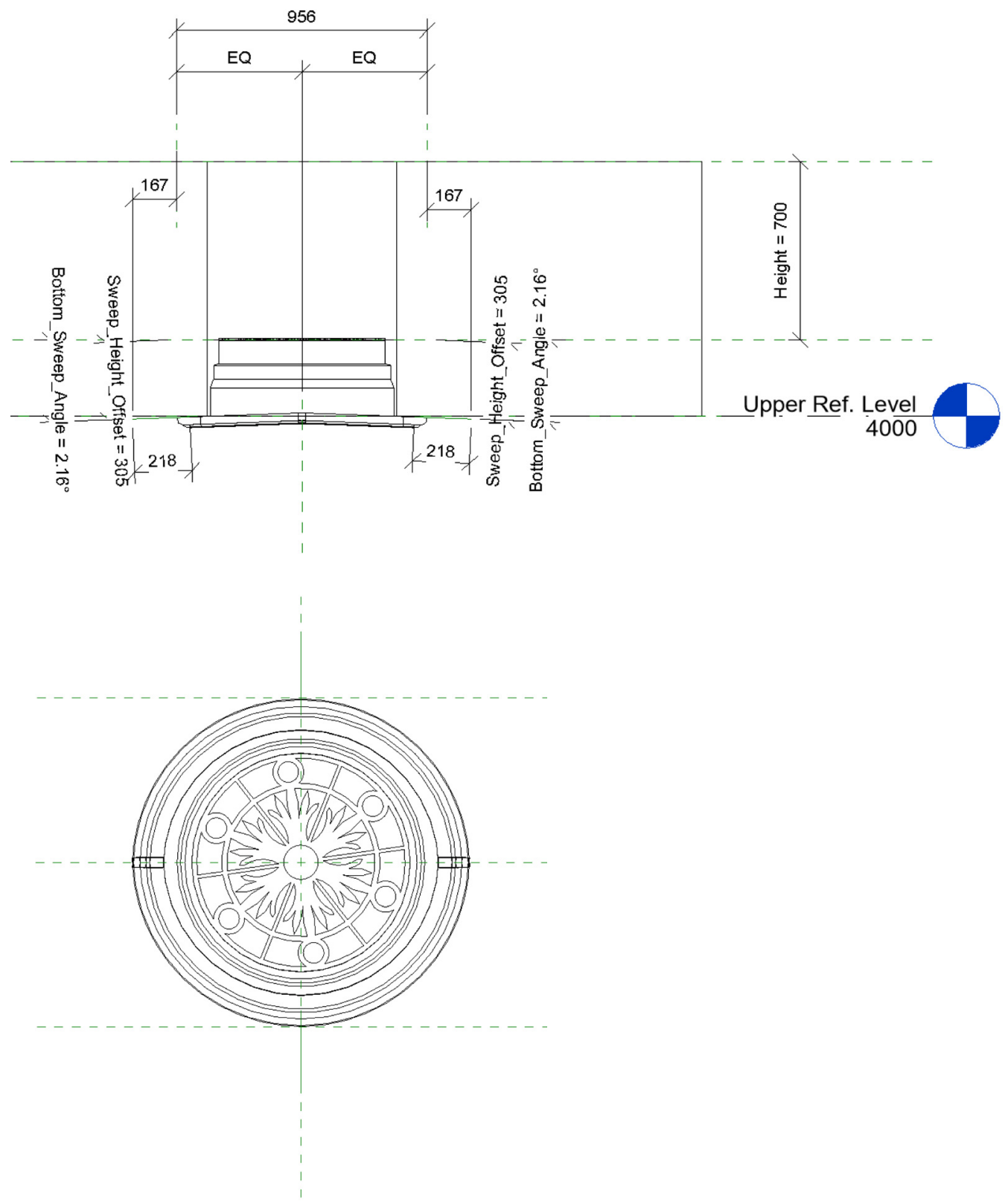

Figure 7. Possil Park Library Ventilation grille parametric family.

Generalisation and Grafting to Historic Standards

Through the 3D model it is possible to obtain the volume and area measurements of the rooms and to analyse the original architectural choices especially concerning the lighting and ventilation of the rooms based on their size. Furthermore, from observing the internal treatment of roofs, it is possible to correlate the similarities with contemporary technical data on cast plaster ceilings. With the extent of the overall survey and the use of the matching techniques noted above, the similarities in the design choices of the vaulted ceilings are evident. It is possible to determine with authority the original architectural intentions in terms of building performance for ventilation.

It is possible to provide pathways back through the trade literature of the time which significantly enhance our probably understanding of their substructure (Figure 8). From building the parametric models, dimensions between structural bays have been noted. For example; in Middlesbrough there are three squared ventilation grilles $0.5 \mathrm{~m}$ wide and placed at a distance of $5.1 \mathrm{~m}$ of each other. The apertures in each side feature 7 vertical windows placed in the lateral walls and each measuring H1730 
$\mathrm{mm} \times \mathrm{W} 1670 \mathrm{~mm}$ with sill height $6100 \mathrm{~mm}$ from the ground level and $3480 \mathrm{~mm}$ from the walkway level. In Loughborough, the main reading room ceiling is domed and hexagonal shape. The room area is $144.37 \mathrm{sqm}$ with ceiling height of $6.73 \mathrm{~m}$. The second reading room instead is a barrel-vaulted ceiling subdivided in three by two ceiling beams. The room area measures $43.14 \mathrm{sqm}$ and curved ceiling height is of $4.83 \mathrm{~m}$ with a pitched skylight $\mathrm{H} 1830 \mathrm{~mm} \times \mathrm{W} 2500 \mathrm{~mm}$ at its apex. These dimensions enable correlation to structural standards and manufactured components that can then be deemed to be likely belong to that heterogeneous system, despite it being hidden from view (Figure 6).
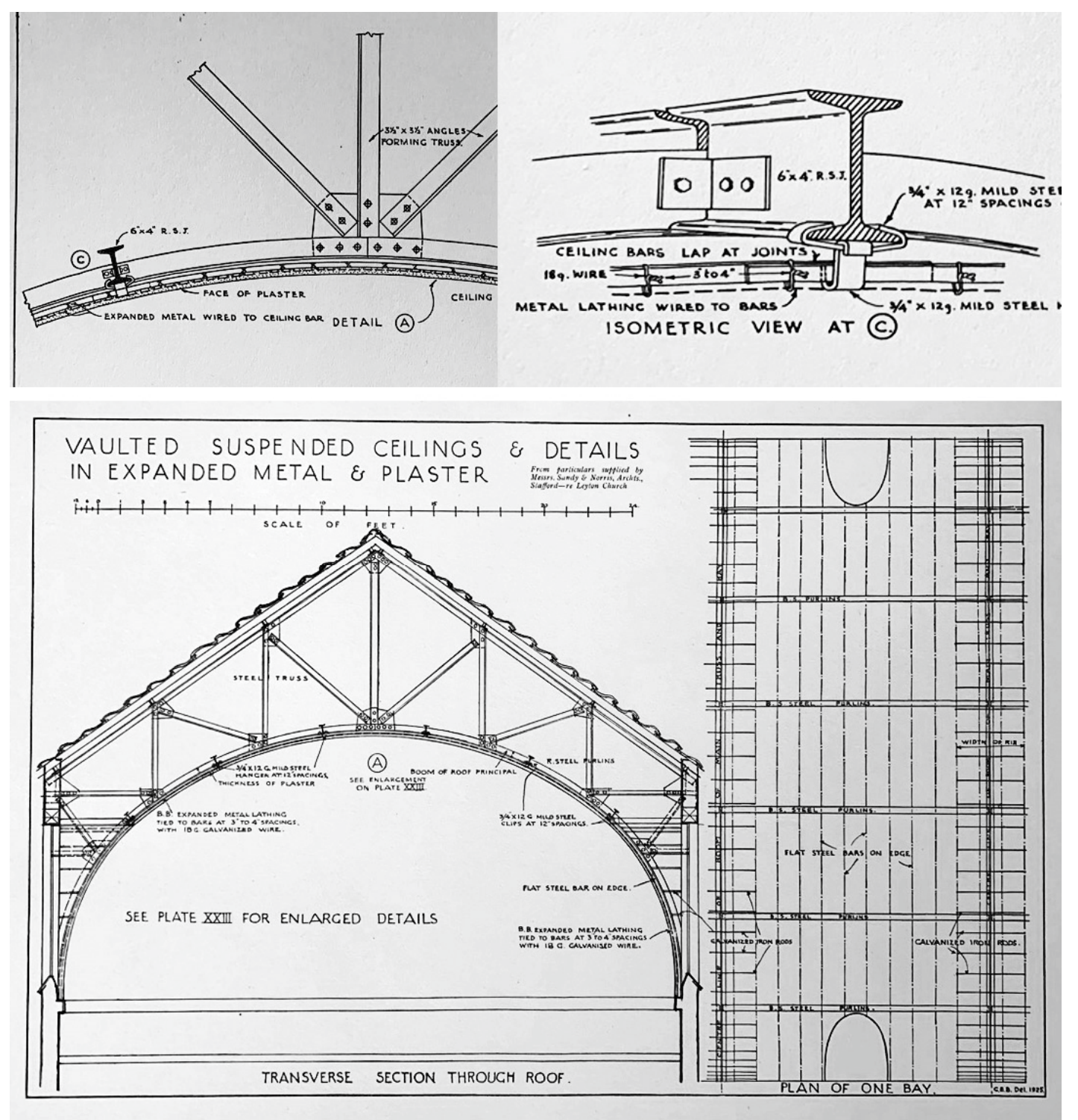

Figure 8. Details from Bankart: Modern plasterwork construction, casting and fixing: fibrous, solid and reinforced 1926 Source: Author.

With reference to a key text on fibrous plaster construction of the time, not only are the decorative details and construction identifiable but also the likely arrangement of the steelwork which can be compared with the spacings evident in the surveyed models [72]. Earlier work outlined the means to identify the likely manufactures of the plaster mouldings and glazing systems [73]. A deeper correlation relevant to all buildings of the era is possible through a comprehensive attempt to digitise historic trade literature. The Common Arrangement of Work Sections (CAWS) is a classification system based on work described trade-by-trade. That system had evolved from nineteenth century 
practices. Uniclass was introduced as a system in 1997 agreed between the professional bodies in the UK and incorporated CAWS [74]. As such it is theoretically possible to pair clauses from historic specifications, where they are available, to current forms for buildings of this era, short-circuiting some of the significant hurdles of HBIM integration in practice.

\subsection{Networking and Delivering the Findings through GIS}

Yang et al. emphasised the "complementarity" of HBIM and GIS in requiring the incorporation of semantic data and set out to challenge the manual demands of integrating them [75]. Figure 9 demonstrates the potential, using GIS, to enable not simply the exchange of best practice for conservation professionals but also for management stakeholders to augment knowledge and interaction in the context of scarce resources.

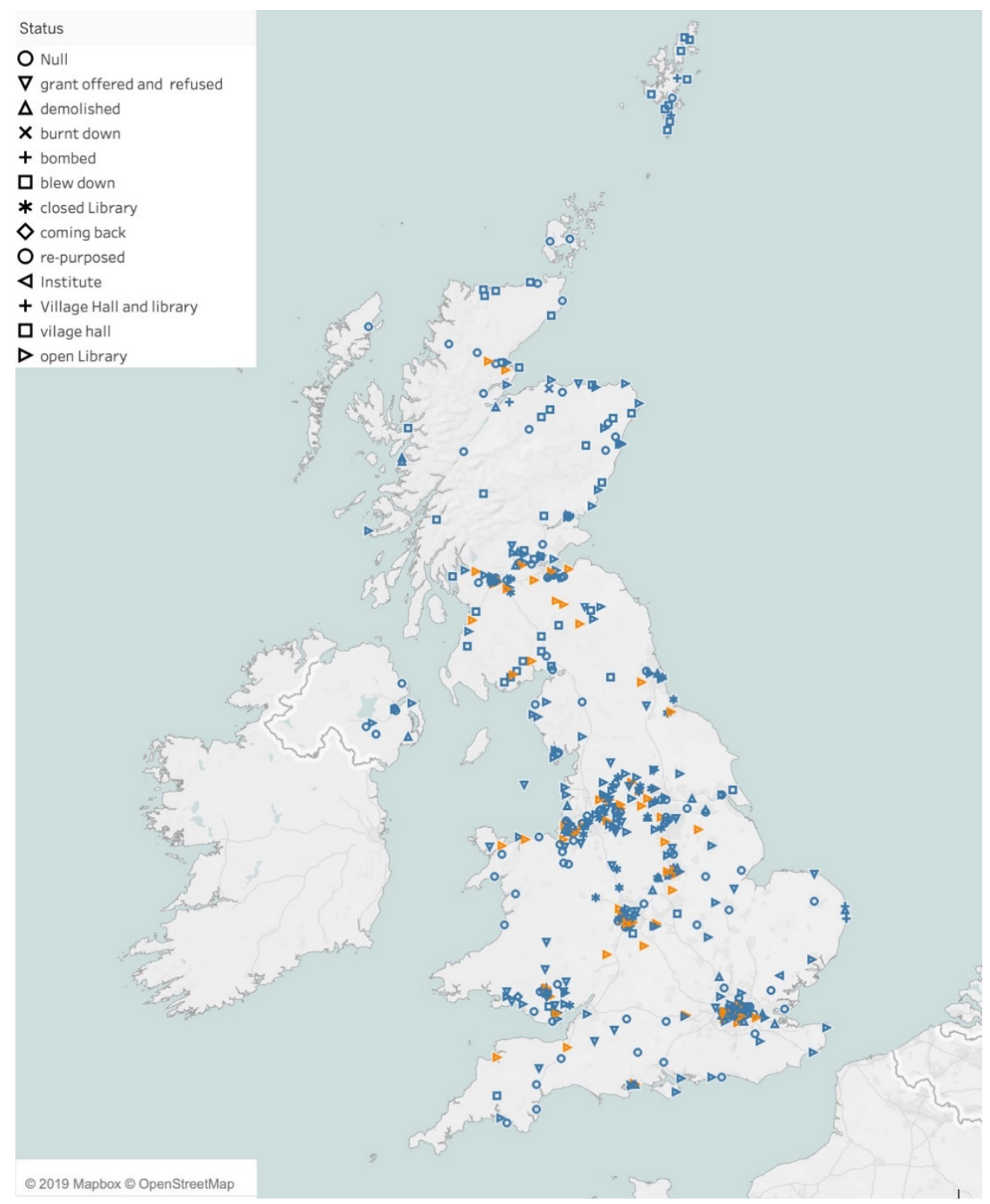

Figure 9. Map of UK Carnegie Libraries in Tableau ${ }^{\mathrm{TM}}$ : Building status denoted by shape, incidence of barrel vaults by orange colour.

The ability to be versatile in reasoning from the general to the particular and vice versa is an aspiration of intelligent heritage documentation but also for future management. Compiling the 
environmental model for one library with the historic technical literature for one manufacturer provides a reference point that we can determine is relevant to a wide and locatable number of buildings. By developing these datasets, we are also engaging stakeholders to share best practice, to add to the pool of knowledge and to acknowledge their geographically disparate but technically similar concerns. Furthermore, it is possible to correlate data in terms of risk regarding for example rooflights and average rainfall with geographic data on library maintenance budgets, socio-economic data and library usage and where recent refurbishments have been successful to anticipate which are the critical potential points of building failure. Such work assists governmental agencies in designation reviews for valorisation purposes but also allows fragmented and financially challenged stakeholders to leapfrog towards best practice for sustainable conservation management.

The next step is to build associated and relevant construction literature to the parametric models that have been created but also to work in a manner that enables subsequent contributions in partnership with industry. Although the NBS is a commercial enterprise (part of RIBA enterprises) and to date its National BIM Library generally contains current commercial products, there is support for contributing bespoke items (including heritage items) using their BIM Object Standard to this open source platform. Given that $48 \%$ of these buildings are listed as of historic interest and that as public buildings, BIM models will be required for them, it is highly probable that those engaged to construct such models will be using this platform in the UK. To this end, the NBS BIM object standard based on the Uniclass reference system is being adopted here as it is a requirement for BS EN ISO 19650 BIM projects. We are working to embed further linkages within its own framework.

\section{Discussion}

This work anticipates the potential to accelerate the assimilation of HBIM models by providing access to pooled resources and potentially enabling data exchange through the use of Digital Doubles. It also takes a step towards the more complex aim of creating life cycle analysis models as a means to facilitate credible assumptions to support design or conservation decisions that can be shared within a designated group. Indeed, the potential to determine and locate survival rates as such presents a significant opportunity to review the lifecycle of an entire philanthropic effort from many perspectives.

Having established the scope of standardisation brought about by the collaboration between architects and librarians in the aim of delivering better library services, previous work has sought to identify the scope of reiteration within development of library architecture. Latterly, in this context, the use of matching techniques and the integration of workflows for scan to BIM for some features has been examined. Having now completed a comprehensive photographic survey of all remaining Carnegie Library buildings in Great Britain and Northern Ireland, the development of deep learning for automatic recognition of such features has also been explored. To this end, we are now able to determine the exact numbers and locations of buildings with these (and other) features in common. One potential for future work will be to expand the sample image dataset to incorporate many other buildings that we may be able to predict commonalities with, by year of building, region, typology, contractor or architect. Whilst accuracy is essential for detailed design decisions, "rules of thumb" or understandings in principle are necessary for strategic decision making. The formulation of critical approaches to refurbishment are under pressure to comply with forceful and often contradictory imperatives of energy use reduction, historic preservation and disabled access to public buildings.

\section{Conclusions}

Aspects of not only technical but also historical understanding are required in order to inform design and conservation management decisions. Historic technical literature becomes part of the collation process for the parametrised objects in order to inform future specifiers, in effect reverse engineering their task of specification. Here, barrel vaults have associated values with regard to their original intended function that are not necessarily obvious. As such it is important to inform conservators or managers of their place within the original design intention, in the case of the barrel 
vaults, as part of an environmental system which might have potential for re-appraisal, not simply an elaborate a decorative scheme, as might at first be assumed.

As noted above, the risk of ignorance in regard to redundant features of buildings is that critical parts of a building's intended performance or character are undermined by a generational gap in the legibility of technology and practice. There exists the potential to substantially augment the power of apprehension by developing better means to share tacit knowledge in conservation and construction, especially for more recent history. A key aspect of that is to understand deeply the context in which original design and specification decisions were made. In the case of the Carnegie Libraries, we are a large step closer to that by virtue not only of the epistolary evidence of design dialogue in archives but also through the significant quantities of built examples. It is not only information for technical building pathology that is enabled here but also for building deeper and more tangible histories.

The methods deployed here have worked between survey, modelling in principle, image classification and mapping in an attempt to draw and share the advantages of generalisable results. Although the sample of buildings referred to here is unique in its extent and consistency for this era, there are disadvantages in the total scope for reverse engineering. Later Twentieth Century buildings may offer considerably more potential for refining an approach based on mass produced building components. In the UK, however, the heritagisation of post-war buildings of a significantly standardised nature is not yet underway to any significant degree. There are further limitations in the potential for generalising approaches to environmental retrofitting indicated here which carry significant responsibilities for balancing priorities for the sustainable conservation of historic buildings. It should therefore not be seen as a means to develop policy to trump expertise, rather as a bridge to augment design decisions which will inevitably remain highly site, budget and context specific.

ICOMOS guidelines assert the significance of documentation and the need to recognise the disciplinary boundaries of the agent. By adding historic data on contractors, suppliers, manufacturers and contemporary specification references to HBIM elements, it is possible to contribute to a rapid amplification of expertise. The data that relates to the wider design intentions, for example to separate the public from books in a library or to rid them from risk of contagion by exaggerated levels of ventilation may be harder to apply unless parametric models are created within typological or historically defined boundaries. The precise purpose of a historic building element can be hard to ascertain, however, in the case of more recent historic buildings where there is a greater legacy of systematic specification and the use of standardised products, there are a significant number of opportunities.

Supplementary Materials: Library list, location and identified components see: http://www.mdpi.com/2076-3417/ 10/4/1283/s1.

Author Contributions: Initial data collation: C.P. with assistance from Mariangela Parisi. and previous work by Graziano Muratore. Methodology, software, validation and writing of matching section: C.P. with assistance from Julien Schroeter, Paul Rosen and Chris Jones. 3d Laser scanning: C.P. with assistance from Mariangela Parisi. and Giovanni Bruschi. Scan registration: C.P. and M.B. CFD modeling and simulation and writing of that section: A.T. Creation of parametric models in REVIT and writing that section, M.B. Conceptualisation, methodology (overall), writing, project administration, photographic and archival surveys, collation of dataset and funding acquisition: O.P. All authors have read and agreed to the published version of the manuscript.

Funding: This work was supported by the Arts and Humanities Research Council "Shelf Life: Re-imagining the future of Carnegie Public Libraries" project [grant number AH/P002587/1].

Acknowledgments: With thanks to the contributions of Paul Rosen and Chris Jones, Julien Schroeter, Giovanni Bruschi, Mariangela Parisi, Graziano Muratore, Clara Larissa Lorenz, which are greatly appreciated.

Conflicts of Interest: The authors declare no conflict of interest. 


\section{References}

1. Ewart, I.J.; Zuecco, V. Heritage Building Information Modelling (HBIM): A Review of Published Case Studies. In Advances in Informatics and Computing in Civil and Construction Engineering, Proceedings of the 35th CIB W78 2018 Conference: IT in Design, Construction and Management, Chicago, IL, USA, 1-3 October 2018; Springer: Cham, Switzerland, 2019; pp. 35-41.

2. Volk, R.; Stengel, J.; Schultmann, F. Building Information Modeling (BIM) for existing buildings-Literature review and future needs. Autom. Constr. 2014, 38, 109-127. [CrossRef]

3. López, F.J.; Lerones, P.M.; Llamas, J.; Gómez-García-Bermejo, J.; Zalama, E. A Review of Heritage Building Information Modeling (H-BIM). Multimodal Technol. Interact. 2018, 2, 21. [CrossRef]

4. $\quad$ National Building Specification. NBS National BIM Report 2018; NBS/RIBA Enterprises Ltd.: Newcastle, UK, 2018.

5. Fai, S.; Sydor, M. Building Information Modelling and the documentation of architectural heritage: Between the 'typical' and the 'specific'. In Proceedings of the 2013 Digital Heritage International Congress (DigitalHeritage), Marseille, France, 28 October-1 Novenber 2013; pp. 731-734.

6. Historic England. BIM for Heritage Developing the Asset Information Model; Historic England: York, UK, 2019.

7. Murphy, M. Historic building information modelling (HBIM). Struct. Surv. 2009, 27, 311-327. [CrossRef]

8. Yusuf, A.; John, C.; Lamine, M.; Gehan Ahmed, N.; Soheir, H.; Khaled, D. Heritage Building Information Modelling; Routledge: New York, NY, USA, 2017. [CrossRef]

9. Dore, C.; Murphy, M. Integration of Historic Building Information Modeling (HBIM) and 3D GIS for recording and managing cultural heritage sites. In Proceedings of the 2012 18th International Conference on Virtual Systems and Multimedia, Milan, Italy, 2-5 September 2012; pp. 369-376.

10. Eastman, C.M. BIM Handbook a Guide to Building Information Modeling for Owners, Managers Designers, Engineers and Contractors, 2nd ed.; Wiley: Hoboken, NJ, USA, 2011.

11. Pauwels, P.; Zhang, S.; Lee, Y.-C. Semantic web technologies in AEC industry: A literature overview. Autom. Constr. 2017, 73, 145-165. [CrossRef]

12. Bruno, S.; De Fino, M.; Fatiguso, F. Historic Building Information Modelling: Performance assessment for diagnosis-aided information modelling and management. Autom. Constr. 2018, 86, 256-276. [CrossRef]

13. Murphy, M.; McGovern, E.; Pavia, S. Historic Building Information Modelling-Adding intelligence to laser and image based surveys of European classical architecture. ISPRS J. Photogramm. Remote Sens. 2013, 76, 89-102. [CrossRef]

14. Rodríguez-Moreno, C.; Reinoso-Gordo, J.F.; Rivas-López, E.; Gómez-Blanco, A.; Ariza-López, F.J.; Ariza-López, I. From point cloud to BIM: An integrated workflow for documentation, research and modelling of architectural heritage. Surv. Rev. 2018, 50, 212-231. [CrossRef]

15. International Council on Monuments and Sites (ICOMOS). Resolutions of the Symposium on the introduction of contemporary architecture into ancient groups of buildings, at the 3rd ICOMOS General Assembly (1972). Available online: https://www.icomos.org/en/resources/charters-and-texts/180-articles-en-francais/charteset-normes/383-resolutions-of-the-symposium-on-the-introduction-of-contemporary-architecture-intoancient-groups-of-buildings-at-the-3rd-icomos-general-assembly. (accessed on 9 December 2019).

16. International Council on Monuments and Sites (ICOMOS). Venice Charter; Article 7; ICOMOS: Venice, Italy, 1964.

17. Prizeman, O. Philanthropy and Light: Carnegie Libraries and the Advent of Transatlantic Standards for Public Space; Ashgate: Farnham, UK, 2012.

18. Black, A. 'We don't do public libraries like we used to': Attitudes to public library buildings in the UK at the start of the 21st century. J. Librariansh. Inf. Sci. 2011, 43, 30-45. [CrossRef]

19. Diara, F.; Rinaudo, F. Open source hbim for cultural heritage: A project proposal. Int. Arch. Photogramm. Remote Sens. Spat. Inf. Sci. ISPRS Arch. 2018, XLII-2, 303-309. [CrossRef]

20. British Standards Institution. Transition Guidance to BS EN ISO 19650; BSI Standards Limited: London, England, 2019.

21. Howell, S.; Rezgui, Y. Beyond BIM: Knowledge Management for a Smarter Built Environment; IHS Markit Publications: London, England, 2018.

22. National Building Information Modelling Standard. What Is the National BIM Standard Project Committee? Available online: https://www.nationalbimstandard.org/faqs (accessed on 7 November 2019).

23. Davis, D. National Building Information Model Standard NBIMS. In National Institute of Building Sciences Facilities Information Council; Infosystems: Washington, DC, USA, 2007. 
24. HM Government. Digital Built Britain. Level 3 Building Information Modelling—Strategic Plan; Core Supplement. Available online: https:/www-ihsti-com.abc.cardiff.ac.uk/CIS/document/309979?PreviousPage=search\% 3fsqm $\% 3$ dAllTerms $\% 26$ AllContent $\% 3$ ddigital $\% 2$ bbuilt $\% 2$ bbritain $\% 2 b l e v e l \% 2 b 3 \% 26$ DocTitle $\% 3 d \%$ 26Abstract\%3d\%26Publisher\%3dhm\%2bgovernment\%26DocNum\%3d\%26Series\%3d\%26Author\%3d\% 26ISBN\%3d\%26YearMin\%3d\%26YearMax\%3d (accessed on 7 November 2019).

25. Eadie, R.; Browne, M.; Odeyinka, H.; McKeown, C.; McNiff, S. BIM implementation throughout the UK construction project lifecycle: An analysis. Autom. Constr. 2013, 36, 145-151. [CrossRef]

26. INCEPTION. Inclusive Cultural Heritage in Europe through 3D Semantic Modelling. Available online: https://www.inception-project.eu/en (accessed on 13 November 2019).

27. Themistocleous, K.; Ioannides, M.; Georgiou, S.; Athanasiou, V. The First Attend for a Holistic HBIM Documentation of UNESCO WHL Monument: The Case Study of Asinou Church in Cyprus. In Euro-Mediterranean Conference; Springer: Cham, Switzerland, 2018; Volume 11196, pp. 408-414.

28. DURAAK. Durable Architectural Knowledge. Available online: http://duraark.eu (accessed on 13 November 2019).

29. Murphy, M.; Corns, A.; Cahill, J.; Eliashvili, K.; Chenau, A.; Pybus, C.; Shaw, R.; Devlin, G.; Deevy, A.; Truong-Hong, L. Developing historic building information modelling guidelines and procedures for architectural heritage in ireland. Int. Arch. Photogramm. Remote Sens. Spat. Inf. Sci. 2017, XLII-2-W5, 539-546. [CrossRef]

30. Quattrini, R.; Battini, C.; Mammoli, R. HBIM to vr. semantic awareness and data enrichment interoperability for parametric libraries of historical architecture. Int. Arch. Photogramm. Remote Sens. Spat. Inf. Sci. 2018, XLII-2, 937-943. [CrossRef]

31. Logothetis, S.; Valari, E.; Karachaliou, E.; Stylianidis, E. Spatial dmbs architecture for a free and open source Bim. Int. Arch. Photogramm. Remote Sens. Spat. Inf. Sci. 2017, XLII-2/W5, 467-473. [CrossRef]

32. Nieto-Julián, J.E.; Antón, D.; Moyano, J.J. Implementation and Management of Structural Deformations into Historic Building Information Models. Int. J. Archit. Herit. 2019, 1-14. [CrossRef]

33. Carnevali, L.; Lanfranchi, F.; Russo, M. Built Information Modeling for the 3D Reconstruction of Modern Railway Stations. Heritage 2019, 2, 2298-2310. [CrossRef]

34. Fassi, F.; Parri, S. Complex Architecture in 3D: From Survey to Web. Int. J. Herit. Digit. Era 2012, 1, 379-398. [CrossRef]

35. Tommasi, C.; Fiorillo, F.; Jiménez Fernández-Palacios, B.; Achille, C. Access and web-sharing of 3D digital documentation of environmental and architectural heritage. ISPRS Ann. Photogramm. Remote Sens. Spat. Inf. Sci. 2019, 42, 707-714. [CrossRef]

36. Brumana, R.; Dellatorre, S.; Oreni, D.; Previtali, M.; Cantini, L.; Barazzetti, L.; Franchi, A.; Banfi, F. HBIM challenge among the paradigm of complexity, tools and preservation: The basilica Di collemaggio 8 years after the earthquake (L'aquila). Int. Arch. Photogramm. Remote Sens. Spat. Inf. Sci. ISPRS Arch. 2017, 42, 97-104. [CrossRef]

37. Chow, L.; Graham, K.; Grunt, T.; Gallant, M.; Rafeiro, J.; Fai, S. The evolution of modelling practices on canada's parliament hill: an analysis of three significant heritage building information models (HBIM). Int. Arch. Photogramm. Remote Sens. Spat. Inf. Sci. 2019, XLII-2/W11, 419-426. [CrossRef]

38. Maiezza, P. As-built reliability in architectural hbim modeling. Int. Arch. Photogramm. Remote Sens. Spat. Inf. Sci. 2019, XLII-2/W9, 461-466. [CrossRef]

39. Macey, F.W. Specifications in Detail; Donhead: Shaftesbury, UK, 2009.

40. Getty. The Getty Vocabularies. Available online: http://vocab.getty.edu/ (accessed on 12 November 2019).

41. CIDOC. The CIDOC Conceptual Reference Model (CRM). Available online: http://www.cidoc-crm.org/ (accessed on 12 November 2019).

42. Parisi, P.; Lo Turco, M.; Giovannini, E.C. The value of knowledge through H-BIM models: historic documentation with a semantic approach. ISPRS Ann. Photogramm. Remote Sens. Spat. Inf. Sci. 2019, 42, 581-588. [CrossRef]

43. National Building Specification. NBS National BIM Report 2019; RIBA Enterprises: Newcastle upon Tyne, UK, 2019.

44. Sacks, R.; Ma, L.; Yosef, R.; Borrmann, A.; Daum, S.; Kattel, U. Semantic Enrichment for Building Information Modeling: Procedure for Compiling Inference Rules and Operators for Complex Geometry. J. Comput. Civ. Eng. 2017, 31, 04017062. [CrossRef] 
45. Morganti, R.; Tosone, A.; Di Donato, D.; Abita, M. HBIM and the 20th century steel building heritage-A procedure suitable for the construction history in ITALY. ISPRS Ann. Photogramm. Remote Sens. Spat. Inf. Sci. 2019, 42, 515-522. [CrossRef]

46. Historic England. BIM for Heritage: Developing an Asset Information Model; Consultation Draft; Historic England: York, England, 2019.

47. Sacks, R. BIM Handbook: A Guide to Building Information Modeling for Owners, Designers, Engineers, Contractors and Facility Managers, 3rd ed.; Wiley: Hoboken, NJ, USA, 2018.

48. Quattrini, R.; Pierdicca, R.; Morbidoni, C. Knowledge-based data enrichment for HBIM: Exploring high-quality models using the semantic-web. J. Cult. Herit. 2017, 28, 129-139. [CrossRef]

49. Acierno, M.; Cursi, S.; Simeone, D.; Fiorani, D. Architectural heritage knowledge modelling: An ontologybased framework for conservation process. J. Cult. Herit. 2017, 24, 124-133. [CrossRef]

50. Xiucheng, Y.; Yi-Chou, L.; Arnadi, M.; Mathieu, K.; Pierre, G. HBIM Modeling from the Surface Mesh and Its Extended Capability of Knowledge Representation. ISPRS Int. J. Geo-Inf. 2019, 8, 301. [CrossRef]

51. Kerr, J.S. The Conservation Plan: A Guide to the Preparation of Conservation Plans for Places of European Cultural Significancea Guide to the Preparation of Conservation Plans for Places of European Cultural Significance, 7th ed.; ICOMOS Open Archive: Sydney, Australia, 2013; ISBN 1863640266.

52. Prizeman, O. How can century-old architectural hierarchies for the design of public libraries be re-interpreted and re-used? J. Cult. Herit. Manag. Sustain. Dev. 2018, 8, 481-494. [CrossRef]

53. Chen, L.; Lu, Q.; Zhao, X. A semi-automatic image-based object recognition system for constructing as-is IFC BIM objects based on fuzzy-MAUT. Int. J. Constr. Manag. 2019, 1-15. [CrossRef]

54. Oreni, D. From 3D content models to HBIM for conservation and management of built heritage. In International Conference on Computational Science and Its Applications; Springer: Berlin/Heidelberg, Germany, 2013; Volume 7974, pp. 344-357.

55. Prizeman, O. Library Data (Version 1) [Data set]. Zenodo, 2020. [CrossRef]

56. Black, A.; Pepper, S.; Bagshaw, K. Books, Buildings and Social Engineering: Early Public Libraries in Britain from Past to Present; Ashgate: Farnham, UK, 2009.

57. Burgoyne, F.J. Library Construction: Architecture, Fittings and Furniture; George Allen: London, UK, 1897.

58. Thompson, G. Planning and Design of Library Buildings; Architectural Press: London, UK, 1973.

59. Prizeman, O. Function and Decoration, Tradition and Invention: Carnegie Libraries and their Architectural Messages. Libr. Inf. Hist. 2013, 29, 239-257. [CrossRef]

60. Dewe, M. Renewing our Libraries: Case Studies in Re-Planning and Refurbishment; Ashgate: Aldershot, UK, 2009.

61. Breisch, K.A. Henry Hobson Richardson and the Small Public Library in America: A Study in Typology; MIT Press: Cambridge, MA, USA, 1997.

62. Papworth, J.W. Museums, Libraries and Picture Galleries, Public and Private: Their Establishment, Formation, Arrangement and Architectural Construction to Which is Appended the Public Libraries Act, 1850 and Remarks on its Adoption by Mechanics and Other Scientific Institutions with Illustrations; Chapman and Hall: London, UK, 1853.

63. Champneys, A.L. Public Libraries: A Treatise on Their Design, Construction and Fittings with a Chapter on the Principles of Planning and a Summary of the Law; B.T. Batsford: London, UK, 1907.

64. Tredgold, T. Principles of Warming and Ventilating Public Buildings: Dwelling Houses, Manufactories, Hospitals, Hot-Houses, Conservatories, Ec and of Constructing Fire-Places, Boilers, Steam Apparatus, Grates and Drying Rooms, 2nd ed.; Improved/with Nine Plates and Several Woodcuts; Josiah Taylor: London, UK, 1824.

65. Rogers, F. Specifications for Practical Architecture: A guide to the architect, engineer, Surveyor and Builder, with an Essay on the Structure and Science of Modern Buildings/Upon the Basis of the Work by Alfred Bartholomew ... , 2nd ed.; C. Lockwood and Co.: London, UK, 1886.

66. Franke, J.; Hellsten, A.; Schlunzen, H.A.; Carissimo, B. The Best Practise Guideline for the CFD simulation of flows in the urban environment: An outcome of COST 732. Int. J. Environ. Pollut. 2011, 44, 419-427. [CrossRef]

67. Amato, G.; Falchi, F.; Gennaro, C. Fast Image Classification for Monument Recognition. J. Comput. Cult. Herit. (JOCCH) 2015, 8, 1-25. [CrossRef]

68. Noelia, O.; Fadi, D.; Abdelmalik, M. Image-Based Delineation and Classification of Built Heritage Masonry. Remote Sens. 2014, 6, 1863-1889. [CrossRef] 
69. Grilli, E.; Farella, E.M.; Torresani, A.; Remondino, F. Geometric features analysis for the classification of cultural heritage point clouds. Int. Arch. Photogramm. Remote Sens. Spat. Inf. Sci. 2019, XLII-2/W15, 541-548. [CrossRef]

70. Pezzica, C.; Schroeter, J.; Prizeman, O.E.; Jones, C.B.; Rosin, P.L. Between images and built form: Automating the recognition of standardised building components using deep learning. ISPRS Ann. Photogramm. Remote Sens. Spat. Inf. Sci. 2019, IV-2/W6, 123-132. [CrossRef]

71. Selvaraju, R.R.; Cogswell, M.; Das, A.; Vedantam, R.; Parikh, D.; Batra, D. Grad-cam: Visual explanations from deep networks via gradient-based localization. IEEE Int. Conf. Comput. Vis. 2017, 618-626.

72. Bankart, G.P.; Bankart, G.E. Modern Plasterwork Construction, Casting and Fixing: Fibrous, Solid and Reinforced; Architectural Press: London, UK, 1926.

73. Prizeman, O.E.C. HBIM and matching techniques: Considerations for late nineteenth- and early twentieth-century buildings. J. Archit. Conserv. 2015, 21, 145-159. [CrossRef]

74. RIBA. Uniclass - Unified Classification for the Construction Industry; RIBA Publishing: London, UK, 1997.

75. Yang, X.; Koehl, M.; Grussenmeyer, P.; Macher, H. Complementarity of historic building information modelling and geographic information systems. Int. Arch. Photogramm. Remote Sens. Spat. Inf. Sci. 2016, XLI-B5, 437-443. [CrossRef]

(C) 2020 by the authors. Licensee MDPI, Basel, Switzerland. This article is an open access article distributed under the terms and conditions of the Creative Commons Attribution (CC BY) license (http://creativecommons.org/licenses/by/4.0/). 